\title{
Sociodemographic determinants of spatial disparities in early childhood caries - an ecological analysis in Braunschweig, Germany
}

Frederic Meyer ${ }^{1)}$, André Karch ${ }^{2),}{ }^{7)}$, Kristin Maria Schlinkmann ${ }^{2)}$, Johannes Dreesman ${ }^{5}$, Johannes Horn $^{2)}$, Nicole Rübsamen ${ }^{2)}$, Henny Sudradjat ${ }^{3)}$, Rainer Schubert ${ }^{4)}$, Rafael Mikolajczyk ${ }^{2), 6), 7)^{*}}$

1) Microbial Communication, Helmholtz Centre for Infection Research, Braunschweig

2) ESME Epidemiological and Statistical Methods Research Group, Department of Epidemiology, Helmholtz Centre for Infection Research, Braunschweig

${ }^{3)}$ Health care center, city of Braunschweig, Head of the department for dentistry

4) Social services department, Health strategy, City of Braunschweig

${ }^{5)}$ Governmental Institute of Public Health of Lower Saxony, Hannover, Germany

6) Hannover Medical School (MHH)

${ }^{7)}$ German Center for Infection Research, site Braunschweig-Hannover

\section{* Corresponding author}

Key words: Early childhood caries, ECC, spatial regression, spatial disparities, risk factors 


\section{Abstract}

Objectives: Early childhood caries (ECC) is a continuing problem worldwide. In Germany, $10 \%$ to $15 \%$ of six-year-old children suffer from severe ECC, and even more have had at least some experience of ECC. The aim of our study was to identify spatial disparities in dental caries experience (measured by dmft (decayed missing filled teeth) index) of children in the city of Braunschweig and to evaluate whether these disparities can be explained by sociodemographic characteristics.

Methods: We examined the dental health of children aged three to six years visiting a daycare center (DCC) in the metropolitan area of Braunschweig between 2009 and 2014 by combining data on dental health from the annual visits of the local health service in Braunschweig's 151 DCCs with aggregated data on sociodemographic factors for Braunschweig's city districts. We assessed longitudinal patterns of change in average $\mathrm{dmft}$ index at district level from 2009 to 2014 using a finite mixture model. We analyzed spatial autocorrelation of the district's average dmft indices by Moran's I in order to identify spatial clusters. With a spatial lag model, we evaluated whether sociodemographic risk factors were associated with high dmft scores and whether spatial disparities remained after adjusting for these sociodemographic characteristics.

Results: The average dmft index decreased slightly $(\beta=-0.048 ; p<0.03$; CI 95\% [-0.079; -0.017]) from 2009 to 2014. The finite mixture model resulted in four different groups of trajectories over time. While three groups showed a decrease in dmft score, one group showed an increase from 2009 to 2014. Moran's I test statistic showed strong evidence for spatial clustering (Moran's I 0.30, p=0.002). A cluster of districts with high dmft values was identified in the center of the city. The spatial lag model showed that both the proportion of unemployed persons (aged 16-65) and the proportion of persons with migration background were associated with the $\mathrm{dmft}$ values at district level. After adjusting for these, no further spatial heterogeneity were observed.

Conclusion: We identified regional clusters for poor dental health in a German city and showed that these clusters can be explained by sociodemographic characteristics. The findings support the need of targeted interventions and prevention measures in regions with less favorable sociodemographic characteristics.

\section{Introduction}


Early childhood caries (ECC) is a disease caused by oral bacteria, which affects the primary dentition of children. The risk of ECC (as a multifactorial disease) is influenced by the composition of the saliva, dietary habits, mineralization and demineralization of the enamel, the composition of the dental plaque and teeth brushing habits (especially by not using fluoridated toothpaste regularly) 1,2. Although it affects only the primary dentition, several long-term consequences have been described, underlining ECC's high public health relevance 3-5: On the one hand, ECC increases the risk for caries of the permanent teeth and poor oral health in later life; on the other hand, associations of ECC with chronic non-communicable diseases such as cardiovascular disorders have been suggested 5, 6. In 2003, the World Health Organization (WHO) released worldwide as well as national targets for oral health to be fulfilled by 2020 . One of these targets is to decrease the number of decayed, missing and filled teeth (dmft index) 7,8 per child below 1 and to increase the proportion of naturally healthy teeth in Germany to $80 \% 9,10$. In 2009 , there was a high heterogeneity of average $\mathrm{dmft}$ indices for six and seven-years-old children described at the level of federal states in Germany, ranging from 1.30 (Saarland) to 2.56 (Thuringia) ${ }^{11}$. Children in Lower-Saxony, the federal state our study was performed in, had an average dmft index of $1.78 .{ }^{11}$. Since all of the German states' average dmft indices are well above the WHO target, it is important to investigate which factors are associated with high caries experience in Germany so that tailored intervention programs can be developed. Previous studies indicate that risk factors for caries experience in Germany can be described on an individual level (including factors like socioeconomic status (SES), low income, migration background ${ }^{12}$, and a low education level $\left.{ }^{13-16}\right)$. All of them are related to poor oral health habits like sugar intake or infrequent teeth brushing 1. Nevertheless, spatial analyses aiming at the identification of local clustering of poor oral health are scarce. A study from Brazil showed a local cluster of good oral health for 12-year-old children in the city center of Piracicaba compared to the (deprived) outlying districts ${ }^{17}$. While the city center showed high SES, the outlying districts are characterized by low SES. It is important to identify spatial clustering of poor oral health for intervention programs. The goal of these programs should be getting in touch with as many families as possible at high risk for ECC. Contacting these families is easier on an aggregated regional than on an individual level. This makes the identification of local clusters of poor oral health to an important target when trying to fulfill WHO goals for oral health in Germany. To date, it is unclear at which regional level spatial heterogeneities in oral health in Germany appear, how big they are, and whether they can be explained by underlying disparities in SES ${ }^{18}$, or whether there are additional factors (e.g. environmental ones) responsible for the observed 
differences. Accordingly, we analyzed data from a German city, Braunschweig, which has a good health reporting system for oral health data and also provides socioeconomic data for the city's districts. The aim of this study was to assess whether there is evidence for clustering of $\mathrm{dmft}$ indices in the city of Braunschweig and to evaluate whether spatial disparities can be explained by sociodemographic factors.

\section{Methods}

In Germany, dental service is provided free of charge for all children. It is however in the responsibility of the parents to decide to make an appointment for their children at the dentist's office. Therefore, many children do not see a dentist before their third birthday ${ }^{19}$. Local health authorities provide therefore annual visits to daycare centers (DCC). The visits are financed by the city while prophylaxis performed by the Health authority is financed by health insurances. All children who joined the annual inspection of teeth (provided by the dental service of the local health authority) in DCCs in the city of Braunschweig from 2009 to $2014(\mathrm{n}=6,279)$ were considered for inclusion in this study. The service is provided for all of the 151 DCCs in Braunschweig every year. In this study, we included only children three to six years old, because this is the risk group for ECC.

Dental health data from 2009 to 2014 were provided by the dental health service of the local health authorities in Braunschweig. Five different dentists performed the oral investigations from 2009 to 2014. While the head of the programme is officially calibrated against the German working group for youth dental care with a Cohen's kappa of 0.88 , the other four are trained internally. However, there is no systematic reporting of training results so that no inter-rater reliability measure can be provided. The database contained all data collected during the annual visits in each of the participating daycare centers in Braunschweig including average dmft index per DCC and the number of investigated children per DCC (N). Based on these data, we calculated the average $\mathrm{dmft}$ index for each district and each year from 2009 to 2014 from the DCC averages by weighting them by the number of investigated children. Aggregated sociodemographic data at district level were provided by the local health authority in Braunschweig. We used the latest available data from 2012, including information about unemployed persons aged 16-65 (in \%) and persons with a migration background (in $\%$ ), for each of the 30 districts. We used the proportion of unemployed people as a proxy for SES at district level. The shapefile data (.shp) used for mapping of the district data was provided by the geo-information service of the city of Braunschweig. Shapefiles store nontopological geometry attribute information for the spatial features of a dataset. In case of our study, this included the city structure of Braunschweig and each city district. Shapefiles consist of three different levels of information (a main file, an index file and a dBASE table). 
The main file is a variable-record-length file in which each record describes a shape with a list of its vertices. The index file contains the offset of the main file record. The dBASE table contains feature attributes with one record per feature. The relationship between geometry and attributes is based on the record number.

\section{Statistical Analysis}

Several statistical methods were applied to investigate the districts' average dmft values over the years 2009 to 2014. For determining the functional form of the overall longitudinal trend in dmft indices, we chose a fractional polynomial approach using the Stata command $\mathrm{mfp}^{20}$. A linear trend was identified as the best one by the fractional polynomial approach (see Fig. 1). In the following analysis we used the same approach to identify longitudinal trends over time for each district. The district's trajectories were assessed for their underlying common patterns. For this purpose, trajectories were described using finite mixture modelling as implemented in the traj package in Stata $12^{21}$. Mixture models can be used to model unobserved heterogeneity in a population. Polynomial functions are used to model the relationship between year and dmft index with model parameters allowed to differ across groups. This way, finite mixture models allow for identification of population heterogeneity not only at the level of dmft index at a given time point, but also in its development over time. We applied the method for target numbers of patterns from one to five; the selection of the optimal number of trajectories was based on the Bayesian Information Criterion (BIC) ${ }^{21,22}$. We increased the number of trajectories used until increasing model complexity led to no further decrease of BIC values.

The spatial autocorrelation was investigated for the districts' average dmft index values from 2014. For this purpose, first the neighbourhood relationship among the number of districts (n) was defined according to the Queen's contiguity rule and based on this a $\mathrm{n} \times \mathrm{n}$ neighboring matrix $\mathrm{W}$ was constructed, where wij $=1$ if district $\mathrm{i}$ and district $\mathrm{j}$ are neighbours and otherwise wij $=0$, respectively ${ }^{23}$. Based on this, Moran's I was calculated ${ }^{24}$. To assess whether sociodemographic factors were associated with poor oral health, we considered the proportion of unemployed persons (aged 16-65) and the proportion of persons with a migration background as explanatory variables for district level dmft data from 2014. With these explanatory variables, we fitted a spatial lag model which is a linear model of the form

$\boldsymbol{y}=\rho \boldsymbol{W}+\boldsymbol{X} \beta+\boldsymbol{\varepsilon}$. 
Here, $\mathrm{y}$ is a vector of observations on the dependent variable (that is the districts' dmft values). $\boldsymbol{W}$ is the neighbouring matrix introduced above. $\boldsymbol{X}$ is a matrix of observations on the explanatory variables, $\boldsymbol{\varepsilon}$ is a vector of independent and identically distributed error terms, and $\rho$ and $\beta$ are parameters. Beta $(\beta)$ is used for the effect size of a predictor in the model. While a beta of 1 represents a one-point increase in the outcome per unit increase in the predictor, a beta of 0 represents no association between predictor and outcome. Rho $(\rho)$ is the spatial lag coefficient and reflects the spatial dependence inherent in the sample data. This coefficient measures the average influence on observations by their neighboring observations. The values range from -1 to 1 , while 0 means no spatial autocorrelation. The spatial lag part of the model $\rho \boldsymbol{W} \boldsymbol{y}$ aims to capture unobserved spatially correlated explanatory variables in order to adjust the estimation procedure for spatial clustering ${ }^{23}$. We investigated an "empty" spatial lag model without explanatory variables. Afterwards, we included the proportion of the unemployed persons and the proportion of persons with a migration background in the model together as well as each variable alone.

To calculate the proportion of variation in dmft at district level, we used the eta-squared $(\eta 2)$ effect size. Eta-squared is defined as:

$\eta 2=\mathrm{SS}_{\text {effect }} / \mathrm{SS}_{\text {total }}$.

$\mathrm{SS}_{\text {effect }}$ is defined as the sums of squares for whatever effect of interest, and $\mathrm{SS}_{\text {total }}$ are the total sums of squares for all effects, interactions, and errors in the model ${ }^{25}$.

All analyses were performed using Stata (longitudinal data) and the open source statistical software R (version 3.2.1). Besides the standard R packages, we used the packages sp, rgdal, maptools, ggplot, RColorBrewer, and ClassInt for visualization of spatial data. For data analysis and data management, we used the packages acs, truncreg, MASS, stats, DescTools, and spdep. The package spdep (and specifically the lagsarlm command) was used for building the spatial lag model.

\section{Results}

We included data from 34,808 children from three to six years; 5,527 of these children were investigated in 2014 representing a mean sample size of 184 children per district (for further information see supplementary table 1). Each DCC could be unambiguously allocated to one of the 30 districts of Braunschweig. The mean size of the DCCs was 42.2 children in 2014 . The average weighted dmft index for Braunschweig as measured in our study decreased from 
1.25 in 2009 to 1.0 in 2014 with a minimum of 0.83 in 2013 (supplemental Tab. $1 ; \beta=-0.048$; $\mathrm{p}<0.03$; CI 95\% [-0.079; -0.017$])$. We identified four different longitudinal trajectory patterns of dmft index values. Three groups of trajectories represented patterns with decreasing dmft indices over time and differed only with respect to their starting values (group 1, 3, 4), while one group (group 2) showed an increasing pattern (Fig. 2A). Most of the districts belonged to group 1 (46.4\%), followed by group 3 (26.6\%), group 4 (19.9\%); only two districts showed increasing dmft values as observed in group 2 (7.1\%) (Fig. 2B) (for further details, see supplemental Tab. 1).

Regarding the sociodemographic data, the proportion of unemployed persons varied between $2 \%$ and $10 \%$, while the proportion of persons with migration background was between $5 \%$ and up to around $37 \%$ (supplemental Tab. 2).

Moran's I test statistic for dmft indices at district level showed a value of $0.30(\mathrm{p}=0.001)$, indicating strong evidence for spatial clustering. This was confirmed when assessing the empty spatial lag model ( $\mathrm{Rho}=0.54 ; \mathrm{p}=0.02$ ) (Table 1$)$. In model 2 , the $\mathrm{dmft}$ index increases by 0.124 points per $1 \%$ increase of the proportion of the unemployed persons (which is described by the $\beta$-coefficient). In model 3 , the dmft index increases by 0.038 points per $1 \%$ increase in the proportion of persons with migration background. Model 4 shows a similar result with slightly decreased values. In all cases, Rho is positive. A cluster of districts with high dmft index values was visually identified in the center of the city (Fig. 3).

The spatial lag model showed that both sociodemographic factors, i.e. the proportion of unemployed persons (aged 16-65) and the proportion of persons with migration background, were associated independently with increased dmft values (Table 1). After adjusting for both variables, there was no evidence of spatial heterogeneity in the model $(p=0.47)$, showing that all spatial heterogeneity in the model is explained by these two factors; they can therefore be seen as the main causes for regional disparities of dmft indices in our study. Moran's I for the residuals of the spatial lag model was $-0.07(\mathrm{p}=0.64)$, further supporting our finding of no residual spatial clustering after adjusting for sociodemographic measures.

\section{Discussion}

In this study, we demonstrated regional clustering of high dmft index values within a mid-size German city (Braunschweig). Regional clustering disappeared after adjusting for spatial sociodemographic disparities. The regional clusters can be explained by the proportion of unemployed persons as well as the proportion of persons with migration background, and even better with a combination of both in a spatial lag model. Moreover, we showed a slight 
decrease in the mean dmft index in Braunschweig from the year 2009 to 2014, indicating an improvement in oral health over the study period.

The strength of our analysis is the good data coverage of dental data, which were collected with long-time experience of the dentists, who are responsible for the dental examinations every year and who are trained regularly. Furthermore, state of the art spatial analyses were performed in order to understand the interplay of geographic and social risk factors. However, there are several limitations to our study. Generally, analysis using aggregated data is prone to ecological fallacy. Since previous individual risk factors analyses provided consistent findings, this does not appear to be a problem in our analysis. As we were interested in spatial effects, the use of spatially aggregated data was appropriate. With regard to spatial effects, there is a possibility that children did not necessarily attend a DCC in the district of their residence, potentially leading to misclassification of $\mathrm{dmft}$ index values and biased estimates of the association between $\mathrm{dmft}$ indices and SES variables. Another problem is the limited availability of variables indicating social disparities. For example, social index of the city of Braunschweig contains also information on proportion of habitants receiving social welfare, but the data for this variable were only available for the end of the year 2012. Theoretically, data for children receiving social welfare were also available and would have been closest to the outcome of dmft in children, but the data come with severe limitations. Not all parents do register children who can possibly get social welfare. It is suggested that more than one third of all children (younger than 15 years old) do not receive state welfare to benefit from it, although they could get it ${ }^{26}$. Social data for all analyses were collected in 2012 and were used for the dmft data from 2014 in the spatial lag model. In times of high national and international mobility, markers of socio-economic status can change rapidly even on an aggregated district level, introducing the chance of misclassification to our study for the years after 2012. However, the major rise in international mobility observed in Europe during the refugee crisis in 2015 happened well after the end of our study so that potential effects on the main study results are estimated as unlikely. Nevertheless, changes in dmft index observed over time could rather be attributable to changes of SES over time (e.g. by changes in local population structure) than to true changes of oral health. Furthermore, SES can be better differentiated if dimensions of education and economic status are both considered. Also, the unemployed are only a subgroup of those of lower SES. Still, in the ecological analysis, it is less important to correctly classify individual persons, and the proxy variable likely served its purpose well. Unfortunately, there were no data available from the dental examination about the composition of the saliva, dietary intake, enamel changes or dental plaques, making it 
impossible to assess the relative effect of these factors in our regression models. While it would have been interesting to examine in detail how the different components of the $\mathrm{dmft}$ index changed over time and were affected by spatial and sociodemographic factors, data were only available aggregated on $\mathrm{dmft}$ level, and could not be tracked down to the individual components. Since there is no water fluoridation in Germany, the fluoridation status of the districts, DCCs or individuals could not be assessed within this study. Topical fluoride applied by the dentists is not covered by the provided data.

Spatial analyses for oral health topics are scarce, and we found only two studies dealing with regional clustering of $\mathrm{dmft}$ index values and the related sociodemographic determinants for these disparities among children younger than six years ${ }^{17,27}$. Comparing our data with a study from Berlin (2008/2009) ${ }^{18}$ that was dealing with oral health data and social data for each district, but did not use spatial analysis, and a study from Piracicaba (Brazil) ${ }^{17}$, our analysis showed similar findings for the association between high average dmft indices and a low social status. The distribution of poor health care and poor SES may differ in different cities depending on cultural and historical aspects: In some cities, the low-income districts are more often located in the center of a city (e.g. Braunschweig); in other cities, low-income areas are the suburban districts (e.g. Piracicaba/Brazil). While Berlin's average dmft index was 1.74 (2009) for six-year-old children, Braunschweig's dmft index for the three- to six-year-old children was 1.25 in 2009, possibly indicating better dental care in the latter. We also showed an improvement from 2009 to 2014 from 1.35 to 1.0, which is consistent with the efforts of local health authorities and their programs to contact high dmft index DCCs more often and communicate with the parents intensively.

However, two districts showed an increase of dmft-index over time. When we compare sociodemographic characteristics in these two districts with the districts with a decreasing $\mathrm{dmft}$ index we find that there is no difference in the proportion of unemployed persons $(p=0.62)$ and the proportion of persons with migration background $(p=0.83)$. As mentioned before, children do not necessarily attend a DCC in the district they are living. District 18 is neighbouring both districts with increasing $\mathrm{dmft}$ indices over time, and is the district with the highest weighted average dmft. Moreover, this district has one of the highest proportions of unemployed persons (8.5\%) and persons with migration background (19.5\%) in the city (for further details see supplementary table 2). One potential reason for the observed increase in the two districts might be that the cross-district distribution of children to child care centers might have changed over time (e.g. by new child care centers close to district 18 ) with more children from district 18 visiting child care centers in the two districts with increasing $\mathrm{dmft}$ indices. Despite the correlation between proportion of unemployed persons and proportion of 
persons with migration background, both variables displayed independent associations with the dmft index in a model mutually adjusting for each other. While the per-one-percentdifference in $\mathrm{dmft}$ values was more than three times higher for the proportion of unemployed than for proportion of those with migration background, it should be borne in mind that there was a much larger variation in the proportion of migrants across the city districts. Based on eta-squared values, both variables explained similar proportion of variation in $\mathrm{dmft}$ at district level. Dietary and behavioral habits have been discussed to be the main pathways of poor oral health in individuals of low SES. Namely, these are more sugar intake and no dental attendance ${ }^{28,29}$. Low SES families spend less money on dietary products ${ }^{30}$. Typical products consumed by low SES persons are bread (mainly white bread), sugars, sweets and cakes as well as sweetened beverages ${ }^{30}$. These products are associated with added fats and low vitamin status. Consequently, children from low SES families have a higher intake of sweetened sugary beverages than children from high SES families ${ }^{31}$. Sweetened sugary beverages have been described to be associated with a higher caries prevalence in a recent study from Georgia/USA ${ }^{32}$. In a similar way, nutritional habits of migrants can be the cause of associations observed for the proportion of migrants; this however, might not be the only explanation. A recent German review concluded that migrants do not have the same benefits from prevention measures, healthcare, and information about oral health issues as persons who were born in Germany ${ }^{33}$. The main reason for that is a lower dental attendance because of sociocultural barriers and problems with the German language ${ }^{33}$.

Our findings showed the need for further interventions to reduce the $\mathrm{dmft}$ index and, thus, the proportion of children with ECC in order to fulfill WHO goals. ECC does not only lead to a poorer quality of life for affected children, but also to greater healthcare costs ${ }^{34}$. Therefore, targeted interventions need to be planned. Interventions on the individual child level, however, are expensive and difficult to implement. More than $93 \%$ of children (three to five years old) in Germany visit DCCs ${ }^{35}$. Hence, DCCs can be used as a place to inform the parents about the importance of prevention for oral health. Regular visits (twice a year) of dentists in DCCs should be implemented in districts at high risk. These could either be defined directly as a mean dmft above 1 (by taking into account $\mathrm{dmft}$ values from recent visits) or indirectly by using aggregated information on the social determinants of high risk identified in this study (e.g. 75th percentile of proportion of unemployed persons or proportion of persons with migration background), During these visits parents and children will receive teaching on the importance of a healthy diet and tooth brushing (including fluoride application) after meals. While high-quality evidence is scarce for population-level 
interventions, there is evidence that indidualized interventions targeted by population-level risk factor analysis can be efficient. Teaching mothers leaving in high risk districts good practice in oral health is, for example, an effective method to prevent children from caries and other oral diseases ${ }^{36,37}$.

Potential population-level interventions could cover the introduction of dental care education in antenatal classes aiming at a harmonized schedule for early dental appointments of newborns. This could be a potentially successful way to conunteract the low proportions $(12 \%)$ of children having seen a dentist in their first two years of live ${ }^{38}$. Another potential intervention could be the combination of paediatric and dental care during early childhood since paediatric care is organized in compulsory visits ${ }^{39}$. Moreover, dentists should identify during their DCC visits those individuals at need for a visit at the dentist's office as recommended by a recent German study ${ }^{40}$. DCC-based interventions targeted to high-risk clusters could thus help in identifying individuals at risk and could support transferring hard to reach populations to individualized dental care. Since all city districts have a good coverage of dentists, there is a sufficient supply of dentists in regions with high dmft who could take over individualized care of individuals at risk.

Knowledge about the SES for each district can be used as a road book for planning these targeted interventions on a DCC level so that interventions can be introduced to those districts which need them most.

\section{Conclusions}

High caries experience is clustered spatially in a medium-sized German city. We identified sociodemographic disparities at district level as the main reasons for spatial heterogeneity. Spatial analyses can thus help not only in identifying but also in predicting regions at high risk for caries if no primary data is available. This can result in targeted intervention programs at district levels. District level interventions allow to reach a higher proportion of the individuals at risk and are therefore more efficient than individual-based interventions. DCCs provide thereby a perfect framework for dentists to examine, teach and fluoridate the children and possibly also the parents.

\section{Conflict of interest:}

The authors declare that they have no conflict of interest. 


\section{References}

1. Behrendt A, Sziegoleit F, Muler-Lessmann V, Ipek-Ozdemir G, Wetzel WE. Nursingbottle syndrome caused by prolonged drinking from vessels with bill-shaped extensions. ASDC J Dent Child. 2001;68(1):47-50, 12.

2. Borutta A, Wagner M, Kneist S. Early Childhood Caries: A Multi-Factorial Disease. OHDMBSC. 2010; Vol. IX(No. 1).

3. Petersen PE, Bourgeois D, Ogawa H, Estupinan-Day S, Ndiaye C. The global burden of oral diseases and risks to oral health. Bull World Health Organ. 2005;83(9):661-9.

4. Bagramian RA, Garcia-Godoy F, Volpe AR. The global increase in dental caries. A pending public health crisis. Am J Dent. 2009;22(1):3-8.

5. Colak H, Dulgergil CT, Dalli M, Hamidi MM. Early childhood caries update: A review of causes, diagnoses, and treatments. J Nat Sci Biol Med. 2013;4(1):29-38.

6. FDI World Dental Federation C. The Challenge of Oral Disease - A call for global action. The Oral Health Atlas. 2nd ed. Geneva. 2015.

7. Klein H, Palmer CE, Knutson JW. Dental status and dental needs of elementary school children. Public Health Reports. 1938;53:751-755.

8. Schuller AA, Holst D. Oral status indicators DMFT and FS-T: reflections on index selection. Eur J Oral Sci. 2001;109(3):155-9.

9. Hobdell M, Petersen PE, Clarkson J, Johnson N. Global goals for oral health 2020. Int Dent J. 2003;53(5):285-8.

10. Ziller S, Micheelis W, Oesterreich D, Reich E. Goals for oral health in Germany 2020. Int Dent J. 2006;56(1):29-32.

11. Pieper K. Epidemiologische Begleituntersuchung zur Gruppenprophylaxe. 2009.

12. Robert Koch-Institut (Hrsg), Bundeszentrale für gesundheitliche Aufklärung (Hrsg).

Erkennen - Bewerten - Handeln: Zur Gesundheit von Kindern und Jugendlichen in Deutschland. 2008.

13. Kuhnisch J, Senkel H, Heinrich-Weltzien R. [Comparative study on the dental health of German and immigrant 8- to 10-years olds in the Westphalian Ennepe-Ruhr district]. Gesundheitswesen. 2003;65(2):96-101.

14. Schenk L, Neuhauser H, Ellert U, Poethko-Müller C, Kleiser C, Mensik G. Kinderund Jugendgesundheitssurvey (KiGGS) 2003 - 2006: Kinder und Jugendliche mit Migrationshintergrund in Deutschland2007. 
15. Rehman MM, Mahmood N, Rehman B. The relationship of caries with oral hygiene status and extra-oral risk factors. J Ayub Med Coll Abbottabad. 2008;20(1):103-8.

16. Geyer S, Schneller T, Micheelis W. Social gradients and cumulative effects of income and education on dental health in the Fourth German Oral Health Study. Community Dent Oral Epidemiol. 2010;38(2):120-8.

17. Pereira SM, Ambrosano GM, Cortellazzi KL, Tagliaferro EP, Vettorazzi CA, Ferraz SF, et al. Geographic information systems (GIS) in assessing dental health. Int J Environ Res Public Health. 2010;7(5):2423-36.

18. Adloff I, Häßler K, Hermann S, Uhlig U, Meinlschmidt G. Mundgesundheit der Berliner Kinder im Schuljahr 2008/2009. 2010.

19. Garcia R, Borrelli B, Dhar V, Douglass J, Gomez FR, Hieftje K, et al. Progress in Early Childhood Caries and Opportunities in Research, Policy, and Clinical Management. Pediatr Dent. 2015;37(3):294-9.

20. Royston P, Ambler G, Sauerbrei W. The use of fractional polynomials to model continuous risk variables in epidemiology. Int J Epidemiol. 1999;28(5):964-74.

21. Jones BL, Nagin DS, Roeder K. A SAS procedure based on mixture models for estimating developmental trajectories. Sociol Methods Res. 2001;29:374-93.

22. Lukočienė O, Vermunt JK. Determining the Number of Components in Mixture Models for Hierarchical Data. In: Fink A, Lausen B, Seidel W, Ultsch A, editors. Advances in Data Analysis, Data Handling and Business Intelligence: Proceedings of the 32nd Annual Conference of the Gesellschaft für Klassifikation e.V., Joint Conference with the British Classification Society (BCS) and the Dutch/Flemish Classification Society (VOC), HelmutSchmidt-University, Hamburg, July 16-18, 2008. Berlin, Heidelberg: Springer Berlin Heidelberg; 2010. p. 241-9.

23. Anselin L. Under the hood: Issues in the specification and interpretation of spatial regression models. . Agricultural economics. 2002;27(3):247-67.

24. Moran PA. Notes on continuous stochastic phenomena. Biometrika. 1950;37(1-2):1723.

25. Brown JD. Statistics Corner: Questions and answers about language testing statistics: Effect size and eta squared. Shiken: JALT Testing \& Evaluation SIG Newsletter. 2008;12(2):38-43.

26. Becker I. Armut in Deutschland: Bevölkerungsgruppen unterhalb der Alg II-Grenze. German Socio-Economic Panel Study (SOEP). 2007:36f. 
27. Antunes JL, Narvai PC, Nugent ZJ. Measuring inequalities in the distribution of dental caries. Community Dent Oral Epidemiol. 2004;32(1):41-8.

28. Hobdell MH, Oliveira ER, Bautista R, Myburgh NG, Lalloo R, Narendran S, et al. Oral diseases and socio-economic status (SES). Br Dent J. 2003;194(2):91-6; discussion 88. 29. Mbawalla HS, Masalu JR, Astrom AN. Socio-demographic and behavioural correlates of oral hygiene status and oral health related quality of life, the Limpopo-Arusha school health project (LASH): a cross-sectional study. BMC Pediatr. 2010;10:87.

30. Darmon N, Drewnowski A. Does social class predict diet quality? Am J Clin Nutr. 2008;87(5):1107-17.

31. Han E, Powell LM. Consumption patterns of sugar-sweetened beverages in the United States. J Acad Nutr Diet. 2013;113(1):43-53.

32. Wilder JR, Kaste LM, Handler A, Chapple-McGruder T, Rankin KM. The association between sugar-sweetened beverages and dental caries among third-grade students in Georgia. J Public Health Dent. 2015.

33. Aarabi G, Reißmann DR, Heydecke G, Farhan D, Kofahl C. Oral health of people with migration background in Germany -a critical evaluation. Deutscher Ärzte-Verlag | DZZ | Deutsche Zahnärztliche Zeitschrift|. 2013;5(68):280-7.

34. Casamassimo PS, Thikkurissy S, Edelstein BL, Maiorini E. Beyond the dmft: the human and economic cost of early childhood caries. J Am Dent Assoc. 2009;140(6):650-7. 35. Statistisches Bundesamt, Wiesbaden. Kindertagesbetreuung in Deutschland 2012. 2012.

36. Kay EJ, Locker D. Is dental health education effective? A systematic review of current evidence. Community Dent Oral Epidemiol. 1996;24(4):231-5.

37. Kowash MB, Pinfield A, Smith J, Curzon ME. Effectiveness on oral health of a longterm health education programme for mothers with young children. Br Dent J. 2000;188(4):201-5.

38. Slack-Smith LM. Dental visits by Australian preschool children. J Paediatr Child Health. 2003;39(6):442-5.

39. Wawrzyniak MN, Boulter S, Giotopoulos C, Zivitski J. Incorporating caries prevention into the well-child visit in a family medicine residency. Fam Med. 2006;38(2):902.

40. Wagner Y, Heinrich-Weltzien R. Evaluation of a regional German interdisciplinary oral health programme for children from birth to 5 years of age. Clin Oral Investig. 2016. 


\section{Figures}

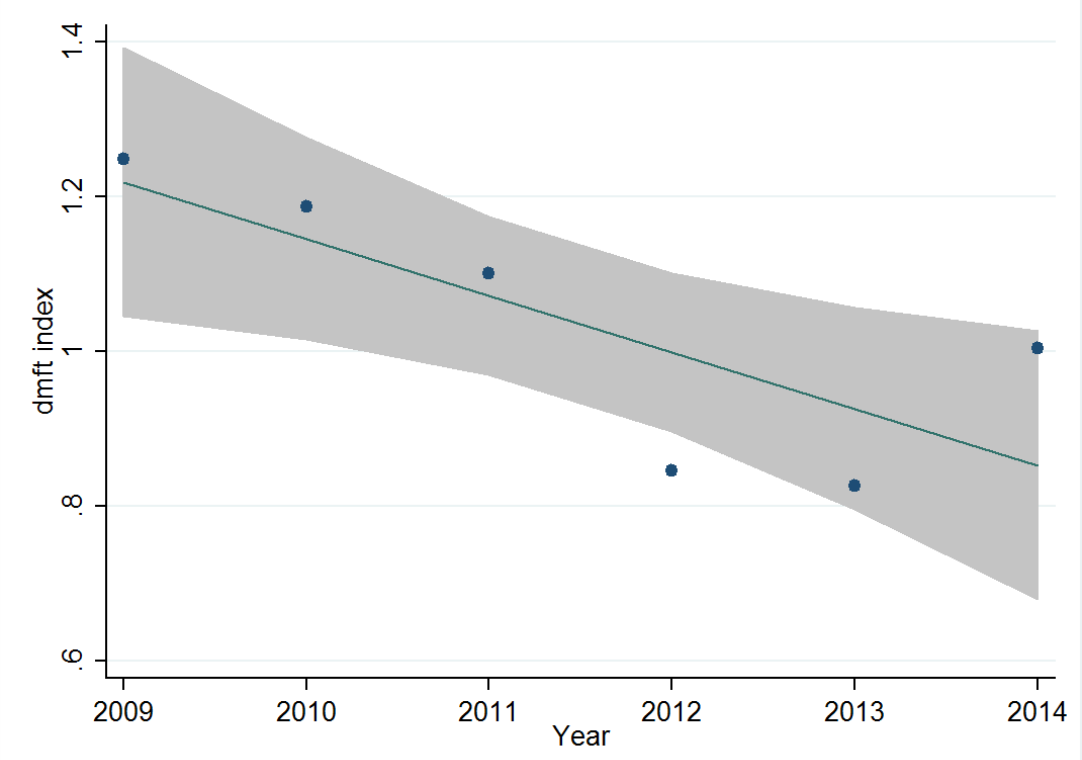

Figure 1: Dmft changes over time on a city level. A fractional polynomial approach was used to identify the best model for further analyses; a linear model was identified as the most likely underlying model in the source population. 


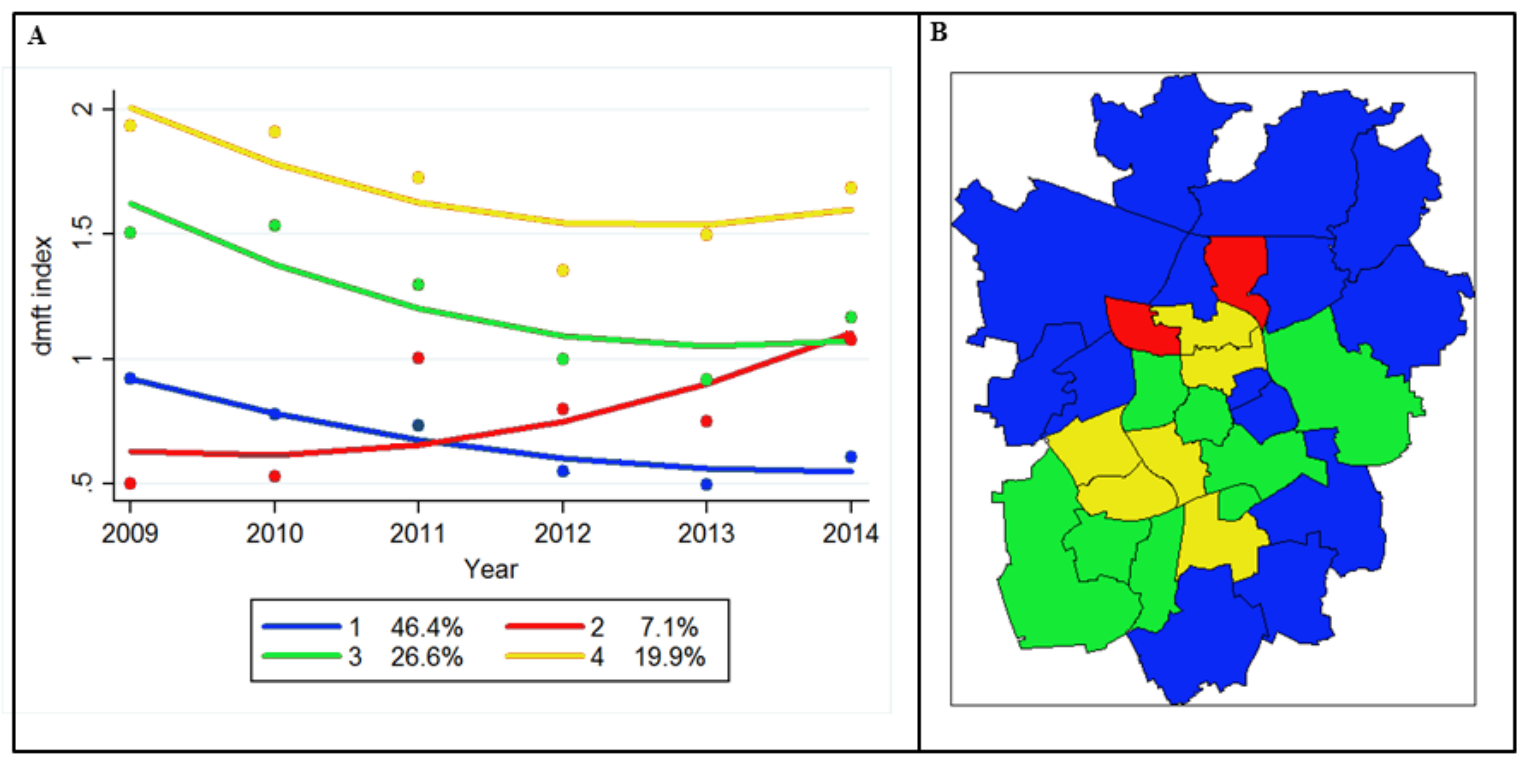

Figure 2: Dmft changes over time: A: The four different trajectory groups show different longitudinal patterns. B: Trajectory groups assigned to the city districts of Braunschweig. For a detailed view, see supplemental Tab. 1. 


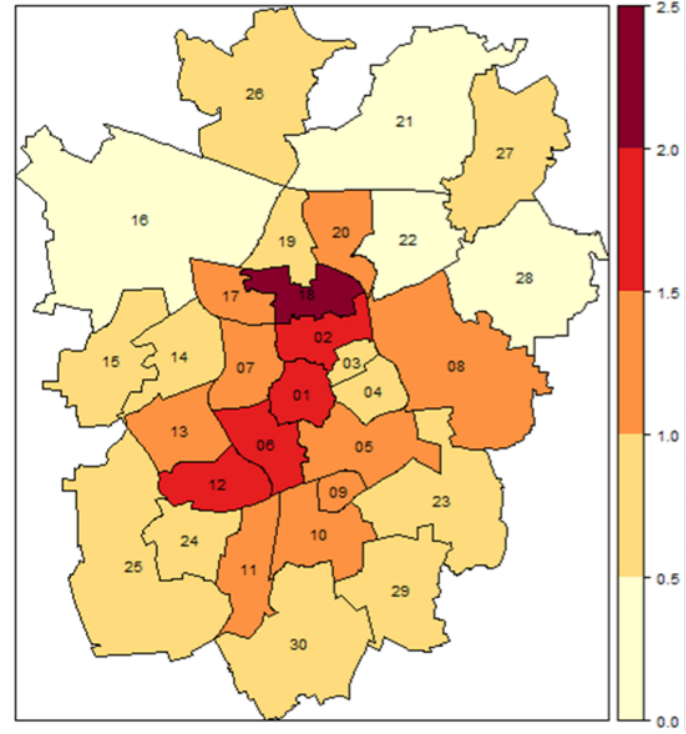

Figure 3: Map of Braunschweig with plotted weighted dmft index for each district in 2014 (Moran`s I $=0.3$ ( $p=0.002)$, digits indicate districts, color scale indicates dmft index). 


\section{Tables}

Table 1: Results of the spatial lag models (each model includes spatial term for districts).

\begin{tabular}{|c|c|c|c|c|c|c|c|c|}
\hline & Co-variables & $\widehat{\boldsymbol{\beta}}$ & $\begin{array}{l}p \\
\text { value }\end{array}$ & $\begin{array}{l}\text { CI 1) } \\
95 \% \\
\text { lower }\end{array}$ & $\begin{array}{l}\text { CI 1) } \\
95 \% \\
\text { upper }\end{array}$ & $\begin{array}{l}\text { Rho } \\
(\rho)^{*}\end{array}$ & AIC $* * *$ & $\begin{array}{l}\text { Eta- } \\
\operatorname{squared}(\eta 2)\end{array}$ \\
\hline $\begin{array}{l}\text { Model } \\
1\end{array}$ & None & & & & & $\begin{array}{l}0.54 \\
(p=0.02)\end{array}$ & 36.142 & - \\
\hline $\begin{array}{l}\text { Model } \\
2\end{array}$ & $\begin{array}{l}\text { Proportion of } \\
\text { unemployed } \\
\text { persons (aged } \\
16-65) * *\end{array}$ & 0.124 & $<0.01$ & 0.075 & 0.173 & $\begin{array}{l}0.23 \\
(p=0.28)\end{array}$ & 25.449 & 0.506 \\
\hline $\begin{array}{l}\text { Model } \\
3\end{array}$ & $\begin{array}{l}\text { Proportion of } \\
\text { persons with } \\
\text { migration } \\
\text { background** }\end{array}$ & 0.038 & $<0.01$ & 0.022 & 0.053 & $\begin{array}{l}0.23 \\
(p=0.28)\end{array}$ & 25.283 & 0.509 \\
\hline \multirow{2}{*}{$\begin{array}{l}\text { Model } \\
4\end{array}$} & $\begin{array}{l}\text { Proportion of } \\
\text { unemployed } \\
\text { persons (aged } \\
16-65)^{* *}\end{array}$ & 0.073 & 0.03 & 0.006 & 0.139 & \multirow{2}{*}{$\begin{array}{l}0.15 \\
(p=0.47)\end{array}$} & \multirow{2}{*}{23.184} & 0.074 \\
\hline & $\begin{array}{l}\text { Proportion of } \\
\text { persons with } \\
\text { migration } \\
\text { background** }\end{array}$ & 0.023 & 0.03 & 0.001 & 0.044 & & & 0.071 \\
\hline
\end{tabular}

* coefficient for residual spatial correlation heterogeneity

$* *$ per $1 \%$ increase

$* * *$ Akaike information criterion

${ }^{1)} \mathrm{CI}$ - confidence interval 